\title{
The Effectiveness of Peer-Led Teaching for Medical Students
}

Poster presented at BAPIO National Conference, London 2019 Peer reviewed by Subarna Chakravorty PhD \& Sunil Daga PhD

\begin{abstract}
Naomi Melamed
Cite as: Melamed, N. (2020) The Effectiveness of Peer-Led Teaching for Medical Students. The Physician vol 6; issue 2; epub 01 Jan 2020; DOI: https://doi.org/10.38192/1.6.2.14

Article Information

Submitted 01 Nov 2019

Published 01 Aug 2020

Open Access - Creative Commons Licence CC-BYND-4.0
\end{abstract}

\section{Background}

In recent years, peer-led teaching has come to the forefront of medical education demonstrating advantages for both medical students and peer-tutors. Moreover, the General Medical Council has highlighted the importance of teaching colleagues to meet the standards proposed in 'Tomorrow's Doctors'. This innovation in medical education has been reflected by a vast increase in the number of peer-led teaching societies at medical schools. However, the effectiveness of peer-led tutoring has been contested.

\section{Aim}

Our study aims to explore the perspectives of thirdyear medical students and student tutors to evaluate the effectiveness of peer-tutoring programs. We also aim to identify potential obstacles peer-tutors may encounter within this process.

\section{Methods}

In 2019, 120 third-year medical students were invited to attend an extra-curricular session delivered by two fourth-year students from a London University. The session focused on developing clinical reasoning skills. All content was approved by a senior member of academic staff. Students and peer-tutors were invited to complete questionnaires following the session to evaluate their teaching and learning experience.

\section{Results}

In total, 102 students attended the session delivered by two peer tutors. Questionnaire responses were received from 95 students and both student-teachers. Of these students, 99\% reported they would attend another session. Around $98 \%$ agreed the session benefited their learning. Both student-teachers stated they feel more confident and competent in clinical reasoning. However, they reported that preparing this session was time consuming.

\section{Conclusions}

Our results suggest that peer-led teaching complements medical school curricula and provides benefits to both students and student-teachers. However, the process revealed several obstacles. These include the limited clinical experience of peer-tutors and time spent preparing sessions. Despite this, we propose that peerled teaching is an innovative concept allowing students a platform to exchange clinical knowledge. 